\title{
Using Reading Quizzes in STEM Classes-The What, Why, and How
}

\section{By Linda C. Hodges, Eric C. Anderson, Tara S. Carpenter, Lili Cui, Tiffany Malinky Gierasch, Sarah Leupen, Kalman M. Nanes, and Cynthia R. Wagner}

Many active learning pedagogies

depend on students' preparing for class in advance. One common

method for holding students accountable for this preparation is the use of reading quizzes. When used thoughtfully, reading quizzes can also actually promote student learning through the testing effect. In this article we describe why and how we use reading quizzes in biology, chemistry, mathematics, and physics courses. We point out the advantages and disadvantages of various delivery methods, such as in class or online, on paper or via clickers, and individual or team based. Our examples highlight the role of these quizzes in promoting student preparedness and in providing feedback to both students and instructors about student learning. Drawing on the literature and our experience, we answer questions that instructors may have about how to use these quizzes to help them achieve their goals for student learning.

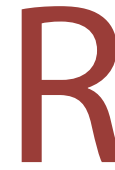
eading quizzes have become a staple of a number of pedagogical formats, such as team-based learning (Michaelsen, Knight, \& Fink, 2004), some flipped classroom approaches (Szpunar, Khan, \& Schacter, 2013, using video as "reading"), and any other teaching choice that relies on students' coming to class prepared (e.g., Klionsky, 2001). Reading quizzes are usually described as credit-carrying, low-stakes, short tests used to assess student comprehension from a preclass preparatory assignment. As Heiner and Rieger (2012) pointed out, reading quizzes prepare students for doing substantive work in class, alert faculty in a timely way to students' learning challenges in the assignment, and free up class time for instructors to deepen student learning.

We would add, however, that a reading quiz also promotes student learning directly through what is called the testing effect. Retrieval events such as testing have in fact been shown to be the most powerful way to promote learning, exceeding the value of additional study time or lectures (for a review, see Roediger \& Karpicke, 2006). In fact, even when students fail to answer questions correctly, the act of retrieval from long-term memory apparently improves the success of subsequent restudy through an effect called testpotentiated learning (Arnold \& McDermott, 2013). Heiner, Banet, and Wieman (2014) studied the specific effects of assigning reading quizzes in an introductory calculus-based physics course and an introductory physiology course, looking both at student class preparation and final exam performance. The majority of students in both classes reported reading more often $(80 \%)$ and feeling that they benefited from reading $(75 \%)$. The authors also found a positive correlation between students' final exam grades and how often they completed the reading quizzes. Anecdotally, we have observed that reading quizzes

- prepare students for in-depth discussions/problem solving in class,

- encourage students to ask higher order questions,

- allow us to include more higher order questions on exams, and

- allow students to answer more higher order questions on exams.

Thus, we view reading quizzes primarily as a way to support student learning, not assess it.

Henderson and Rosenthal (2006) noted problems in using reading quizzes. For example, writing questions at an appropriate level can be difficult. They also maintained that the approach is teacher centered and does not focus on students' own questions about the reading. In this article we address these challenges by describing eight cases of faculty using reading quizzes in biology, chemistry, mathematics, and physics courses to prepare students for active learning formats and to help them learn course concepts. We discuss what reading quizzes are in each 


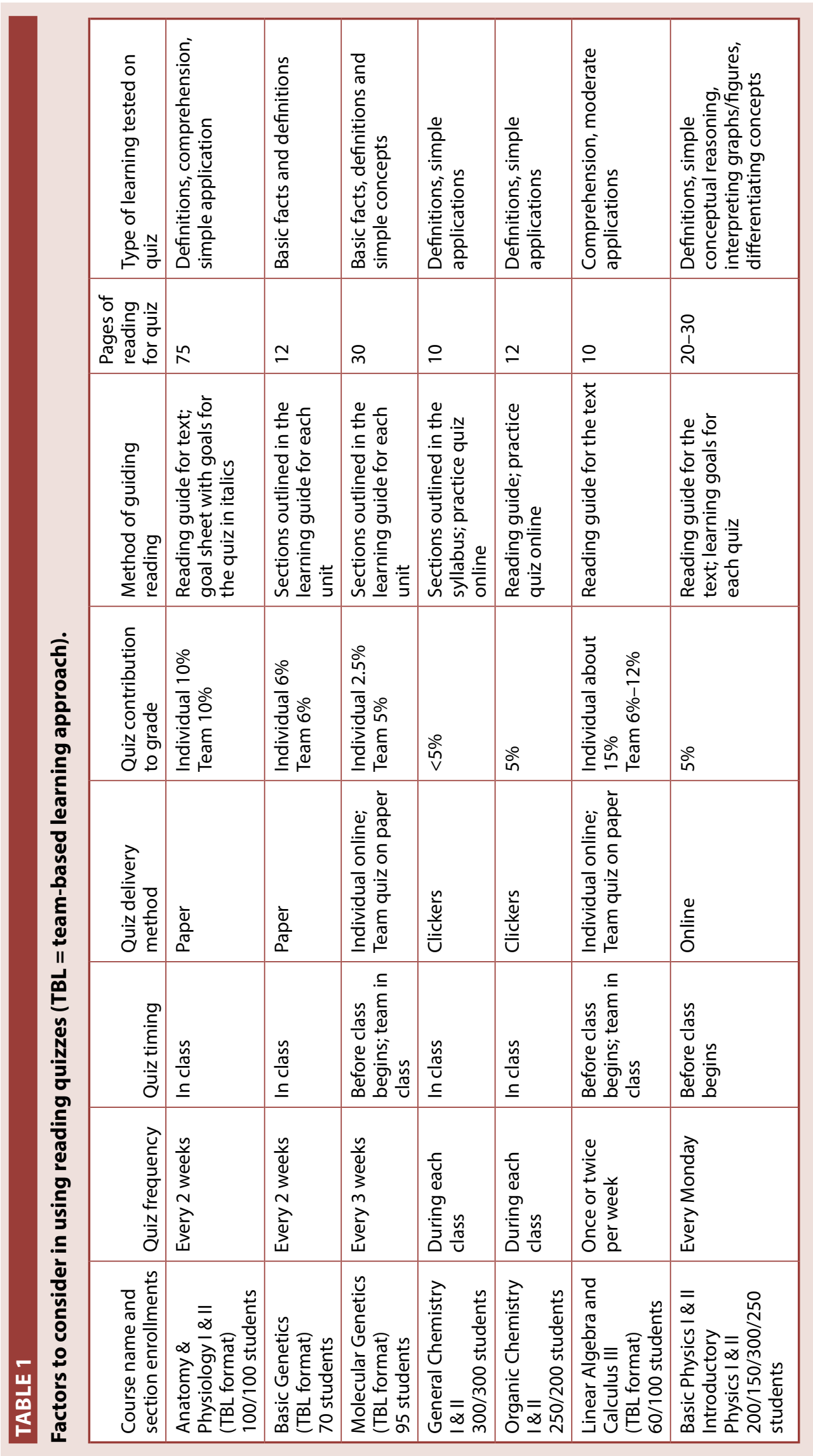

class, why we choose to use them, and how we incorporate the quizzes into the course plan. These key features of each instructor's use of reading quizzes are captured in Table 1 and discussed in the next sections. We also provide a sample reading quiz question for each class (Figure 1) and a list of advantages and disadvantages of the different formats for reading quizzes (Table 2). We then draw on our experiences and the literature to answer common questions instructors may have on why and how reading quizzes can support student learning.

\section{Two cases in biological sciences}

Author Leupen teaches a two-semester sequence of anatomy and physiology for allied health students using a team-based learning approach (TBL). In the TBL format, students take a reading quiz individually and in their teams as part of the Readiness Assurance Process. She administers quizzes during class at the beginning of each of the seven units. The team quizzes are administered using the Immediate Feedback Assessment Technique (IF-AT) scratch-off cards (http:// www.epsteineducation. com/home/) that allow students to receive immediate feedback. The quizzes require students to retrieve from memory fundamental ideas and concepts necessary for the application exercises. 


\section{FIGURE 1}

\section{Sample reading quiz questions. Asterisks indicate correct answers.}

\section{Anatomy \& Physiology}

If the collecting duct of the kidney is at 1000 Osm (osmolar) and the nearby interstitial fluid is at 1400 Osm, water will move:

a. from the interstitial fluid to the collecting duct

b. it will not be able to move in either direction

c. from the collecting duct to the interstitial fluid*

$\mathrm{d}$. it will move equally in both directions (no net movement)

\section{Molecular Genetics}

The center of the controversy over embryonic stem cell research is

a. the unproven usefulness of stem cells to treat human disorders

b. the realization that these cells are pluripotent rather than totipotent

c. the fact that the embryos are mostly those unused by in vitro clinics

d. the difference of opinion about whether these embryos are persons*

\section{General Chemistry}

Which element(s) would you expect to behave chemically most like Sr?

a. $\mathrm{Mg}^{*}$

b. $\mathrm{Rb}$

c. $Y$

d. all of the above

\section{Organic Chemistry}

What is the relationship between these structures?

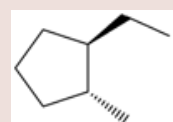

a. same compound

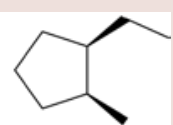

b. enantiomers

\section{c. diastereomers*}

\section{Linear Algebra}

How many solutions can a linear system of equations have if that system is consistent?

a. exactly one

b. any number other than 0

c. none, one or infinitely many

d. infinitely many

e. one or infinitely many*

\section{Multivariable Calculus}

Suppose that the origin is on a piece of paper. The vector $a$ is going from the origin to the right, and the vector $b$ is starting from the origin and pointing straight out of the page toward you. If $(b \times a)$ starts at the origin, in which direction does it point? a. left

b. down

c. up*

d. into the page (away from you)

e. $(b \times a)=0$

\section{Basic Physics (algebra based)}

The term $p_{0}$ that appears in the equation $p=p_{0}+\rho g d$ represents

a. the pressure of the gas above the liquid*

b. the pressure at the bottom of the liquid

c. the density of the liquid

d. the density of the gas

\section{Introductory Physics (calculus based)}

A thick wire and a thin wire of the same length and same material have the same electric field in them. Which of the following will be different for the two wires?

a. potential difference

b. current*

c. current density

d. all of the above
This learning is reinforced via the team discussion. Because she also uses the quizzes to develop students' responsibility for their own learning, she finds the in-class mode of delivery most effective. Students are held individually accountable on their own quiz, and the peer pressure of the team quizzes provides an additional incentive for students to prepare.

Author Wagner teaches two genetics courses: one at the 100-level for nonmajors and one at the 300level for biology majors. In both cases, she also uses a TBL approach. The quizzes help keep her students from falling behind, an especially important goal in her introductorylevel class. Holding students accountable for the basic information in the readings frees up class time for problem solving and in-depth applications. Given the large amount of content covered in the 300-level genetics course, she administers the individual reading quiz online via the course management system to save class time. She then administers the team quiz in class.

\section{Two cases in chemistry}

At our institution, two semesters of general chemistry are prerequisite to the two-semester organic chemistry sequence. Most students are chemistry, biology, biochemistry, and engineering majors or preprofessional students. Author Carpenter teaches the general chemistry sequence and author Gierasch teaches the organic chemistry sequence. Both instructors use a version of a flipped-class pedagogy in which students complete a reading assignment and a practice quiz using a publisher's online program before class. Both administer a short follow-up quiz in class using an audience response system, that is, clickers. Using clickers in class ameliorates some of the concerns about using unproctored on- 
line quizzes. The clicker quizzes encourage student preparation for class and enable a higher level of discussion and problem solving in class. Author Carpenter finds that the questions also provide students with a summary of the day's readings.

The clicker questions are short and responses are collected quickly (30 seconds), so they assess what the students know, not what they can look up from the reading. The public yet anonymous nature of clicker questions provides feedback to students, and the histogram of the responses lets instructors and students alike know what concepts the class did and did not assimilate from the reading. Because the questions must be multiple choice or true/false, however, the correct responses can sometimes overestimate the number of students who really understand the concept behind the answer. Author Gierasch, for example, thus makes sure to probe the class about the "why" of the answer regardless of whether students picked the correct response.

\section{Two cases in mathematics}

Author Nanes teaches linear algebra and the third semester of calculus, both intended for first- to secondyear mathematics, physics, engineering, and economics majors. He uses a modified version of the TBL format. Students go through Readiness Assurance Processes one to two times a week. The individual quizzes are completed online before class, and the team quizzes are administered in class. He uses the online reading quizzes to prepare students for class and capitalizes

\section{TABLE 2}

\section{Logistics to consider in using reading quizzes.}

\begin{tabular}{|c|c|c|}
\hline & Advantages & Disadvantages \\
\hline \multicolumn{3}{|l|}{ Guidance provided } \\
\hline None & None & $\begin{array}{l}\text { Students may not know how to read for } \\
\text { understanding and may accuse faculty of } \\
\text { being unfair }\end{array}$ \\
\hline Model reading quizzes in class & Students see our learning expectations & Students may not remember from class \\
\hline Provide reading goals & Students see our learning expectations & $\begin{array}{l}\text { Students may misinterpret level required for } \\
\text { learning }\end{array}$ \\
\hline Provide reading questions & Students see our learning expectations & Students may study only those questions \\
\hline \multicolumn{3}{|l|}{ Delivery method } \\
\hline In class & $\begin{array}{l}\text { Retrieval event for students } \\
\text { Possible team learning }\end{array}$ & $\begin{array}{l}\text { Takes time from class } \\
\text { May require some grading }\end{array}$ \\
\hline -Paper & $\begin{array}{l}\text { No technology required } \\
\text { IF-AT forms allow teams immediate feedback }\end{array}$ & May require some grading \\
\hline -Clickers & $\begin{array}{l}\text { Immediate feedback } \\
\text { Can display class results } \\
\text { Grading is automatic }\end{array}$ & Requires the technology \\
\hline Online & $\begin{array}{l}\text { Flexible timing for students } \\
\text { Students may review before class } \\
\text { Requires no class time }\end{array}$ & $\begin{array}{l}\text { Students may use sources other than self } \\
\text { and lose advantage of retrieval for learning }\end{array}$ \\
\hline \multicolumn{3}{|l|}{ Frequency } \\
\hline At beginning of each class & $\begin{array}{l}\text { Less reading for each quiz } \\
\text { Students are prepared for each class }\end{array}$ & $\begin{array}{l}\text { Takes time from each class (if in class) } \\
\text { Possibly more grading }\end{array}$ \\
\hline At the beginning of units & $\begin{array}{l}\text { Less class time taken by quizzes (if in class) } \\
\text { Students may be less stressed by fewer quiz- } \\
\text { zes }\end{array}$ & More reading for each quiz \\
\hline
\end{tabular}

Note: IF-AT = Immediate Feedback Assessment Technique 
on the idea that students may treat these as open-book quizzes. So instead of quizzing on basic definitions, he uses the reading quizzes to engage students in slightly more complicated applications and reading comprehension. Students do not receive feedback on their answers until after they complete their team quizzes in class. The bulk of class time can then be used to layer complexity onto the basic concepts that the students gained from their reading quizzes.

\section{Two cases in physics}

Authors Anderson and Cui both teach one of the two semesters of an algebra-based introductory physics sequence for biology majors and of a calculus-based introductory physics sequence for engineering and physics majors. Both Anderson and Cui want to spend class time having students practice and receive feedback on the chains of conceptual reasoning and complex problem solving required for homework and exams. They thus ask students to learn definitions, relationships, and basic patterns of reasoning and problem solving from their reading before class. The reading quizzes also help students become more aware of what they know and what they don't. Thus, they administer the quizzes online before class and allow students three attempts with only the final score counting toward the grade. Students receive feedback via guiding questions. Allowing multiple attempts on quizzes helps ease student anxiety and emphasizes the instructors' goal of using these quizzes to develop students' awareness of their understanding before class.

\section{Discussion}

From these examples we can see that the most important factor in deciding if and how to use read- ing quizzes are the goals that such quizzes serve in the class. On the basis of this and other contextual factors, we address common questions about the construction and use of reading quizzes below.

\section{What kinds of questions should I ask on reading quizzes?}

Writing reading questions at the appropriate level is critical. Our main goal is to prepare students to participate meaningfully in class activities. Because all of us teach large-enrollment classes, we use mostly multiple-choice formats for the questions (Figure 1). In general, we ask students lower order concept-driven questions drawing on simple definitions and exemplifying simple applications (Sibley \& Ostafichuk, 2014). We also ask students to solve basic problems such as those found in textbook examples and interpret graphs and figures from the text. And we ask students to connect new ideas to their prior learning.

The Team-Based Learning Collaborative (2013) recommends that reading quizzes include about one third of the questions at the level of knowledge or recall and two thirds at the level of application using Bloom's taxonomy (Anderson \& Krathwohl, 2001). However, asking students questions that are lower order cognitively can lead students to expect that this is the highest level of learning they will need in the course. We address this issue in several ways. We first clearly explain to students, both in class and in written materials, the strategy of the course design, including the role of the reading quiz as encouraging and testing the achievement of lower order chapter goals. In class we ask students to explain their reasoning for their answers to the quiz questions, thus taking the questions themselves, as well as students' understanding of them, to a higher level. We then reinforce these approaches by using class time to ask additional questions or problems at the application and analysis level of Bloom's taxonomy. The majority of class time is spent on these activities to emphasize the level of thinking required to be successful in the course on exams and projects.

\section{How much guidance should I give students in preparing for the reading quizzes?}

The cognitive demand of reading science is such that novices in our disciplines may be unclear about what ideas to focus on when reading (van den Broek, 2010). We provide guidance on our expectations for students for the reading quizzes, either through our objectives on the syllabus, via reading quiz goals, or by providing reading questions (Table 2). We take into account how long or how dense the readings are in thinking about how much guidance to provide students. In some cases we administer reading quizzes more frequently so that the number of new ideas and concepts being covered is more manageable. If we administer reading quizzes less often, for example, only at the beginning of a unit, we provide more specific instructions about what topics the reading quiz includes. The general rule is: The longer the reading students must do on their own, the more guidance they need.

We realize, however, that providing very specific guidelines on what will or will not be included on reading quizzes can lead students to simply page through the text to find answers to questions. In some cases instructors address this challenge by assigning reading sections without specific guidelines. Instead the instructor uses sample clicker questions during the first week of class that model the kind of learning she expects students to gain from their reading. 
How should I administer the quiz, for example, in class or online, on paper or via audience response system?

Each delivery format for the quizzes has various advantages and disadvantages depending on one's goals for students' learning (Table 2).

In-class quizzes, though they take up class time, hold students individually accountable and maximize the potential of the testing effect. When administered by clickers, the grading is automatic, and student results can easily be transferred to a gradebook in a course management system. Students also receive feedback quickly, a key factor in promoting student learning. Likewise, when individual quizzes are given in class on paper as a prequel to a team quiz (TBL formats), students are held individually accountable and receive feedback during the team quiz by using the scratch-off cards. In addition, the team discussion aspect of this quizzing option enhances student learning by requiring students to explain and defend their answers.

Online quizzes free up class time and allow flexibility in when students do their preparation. Students can receive feedback immediately, which can encourage them to study those concepts they missed before class. Instructors can view student results before class and adjust class activities to address students' difficulties. The disadvantage is, of course, that in an unproctored environment, students may use other sources rather than independently testing their own understanding. If they do so, they lose the benefit of retrieval for learning. Some of us address this concern by giving follow-up, in-class quizzes either in teams (in TBL formats) or via individual clicker questions. Other strategies to encourage students to work alone and not share or copy questions from online quizzes include setting a fairly short time limit for the quiz and randomizing the order of questions. A different perspective, however, as exemplified by author Nanes, is to allow students to use other sources, but as a result, ask questions that probe a little more deeply into their understanding or connect to their prior knowledge. Constructed appropriately, these quizzes, too, can provide the advantage of the testing effect. An issue can arise if instructors allow students two or three attempts on online quizzes because students may start guessing after the first attempt. We thus emphasize to students that the quizzes both promote their learning and allow them to assess their learning and that they will not benefit from them if they simply guess on their second or third attempts.

\section{How frequently should I administer a reading quiz?}

We consider the amount or conceptual difficulty of the reading in deciding on the frequency for the reading quizzes, as well as how the reading quizzes factor into class goals and activities (Table 2). For example, those of us using online quizzes or in-class clicker quizzes often require them for every class as a prelude to group activities. In TBL, however, the team quizzes are critical in promoting students' accountability for their own learning, building team cohesion, and deepening student understanding through peer discussion. The extra time that takes, however, limits the frequency of reading quizzes usually to once a week or less. In some cases, we use this process only at the beginning of units. In math, however, the instructor makes this process the focus of most class sessions by asking somewhat more complex reading questions that students explore further during class. Finally, we also balance the frequency of reading quizzes with other assigned homework in the class - for example, problem sets.
How do I build on reading quizzes in subsequent in-class plans?

Asking students to prepare for class through reading quizzes allows us to design in-class activities that extend student learning. Student performance on the quizzes and inclass exercises provide feedback on how well students are mastering content, both for instructors and students. We then use that information for designing additional support for students. This approach illustrates a learner-centered way to use reading quizzes. For example, both Leupen and Wagner in their biology courses use an individual quiz followed by a team quiz as part of a TBL strategy. As they collect the team scratch-off cards, they note any questions that more than one team got incorrect and immediately give a 3-5 minute minilecture on the topic and answer any further questions. During the remainder of class, as teams answer questions involving application of concepts, students' knowledge of the concepts on the quiz is assumed. If needed, the instructor calls on students at random to clarify any lingering confusion for their peers. In another example, Carpenter uses the results from these quizzes to help direct her coverage of class topics and the particular problems she has students work on that day. She also uses the results to determine areas for additional supportfor example, additional handouts and/or special topic-focused office hours.

\section{How should I factor reading quizzes into a student's grade?}

Science texts are very different from the narrative texts students read and often include too many new vocabulary words and too few explanations. Thus, we count reading quizzes as relatively lowstakes assessments, ranging from 
$2.5 \%-10 \%$ of the student's overall grade in the course. Basically, reading quizzes need to count enough so that students make the effort to read for understanding, but not so much that students feel penalized or overly anxious. Rather, we want to help students learn how to read in the discipline and thus promote their feelings of self-efficacy and enhance their motivation.

\section{Conclusion}

Depending on instructors' goals for their classes, reading quizzes can be a productive way to help students learn how to learn on their own, prepare them for meaningful in-class work, and promote their effective learning of course concepts through the testing effect. Asking questions at an appropriate level can be challenging, but instructors can support students by providing guidance to them on what they should focus on in the reading. Instructors may also draw on their knowledge of student abilities from past experience with the course and from in-class activities to design questions at an effective level. By using the results of reading quizzes to design follow-up class activities, instructors validate this approach as a learning-centered formative assessment that informs both instructor and student.

\section{References}

Anderson, L. W., \& Krathwohl, D. R. (Eds.). (2001). A taxonomy for learning, teaching and assessing: A revision of Bloom's Taxonomy of educational objectives: Complete edition. New York, NY: Longman.

Arnold, K. M., \& McDermott, K. B. (2013). Test-potentiated learning: Distinguishing between direct and indirect effects of tests. Journal of Experimental Psychology:

Learning, Memory, and Cognition, 39, 940-945.

Heiner, C. E., Banet, A. I., \& Wieman, C. (2014). Preparing students for class: How to get $80 \%$ of students reading the textbook before class. American Journal of Physics, 82, 989-996.

Heiner, C., \& Rieger, G. (2012). Preclass-reading assignments: Why they might be the most important homework for your students. Retrieved from http://www.cwsei. ubc.ca/resources/files/Pre-reading guide_CWSEI.pdf

Henderson, C., \& Rosenthal, A. (2006). Reading questions: Encouraging students to read the text before coming to class. Journal of College Science Teaching, 35(7), 46-50.

Klionsky, D. J. (2001). Constructing knowledge in the lecture hall: A quiz-based, group-learning approach to introductory biology.

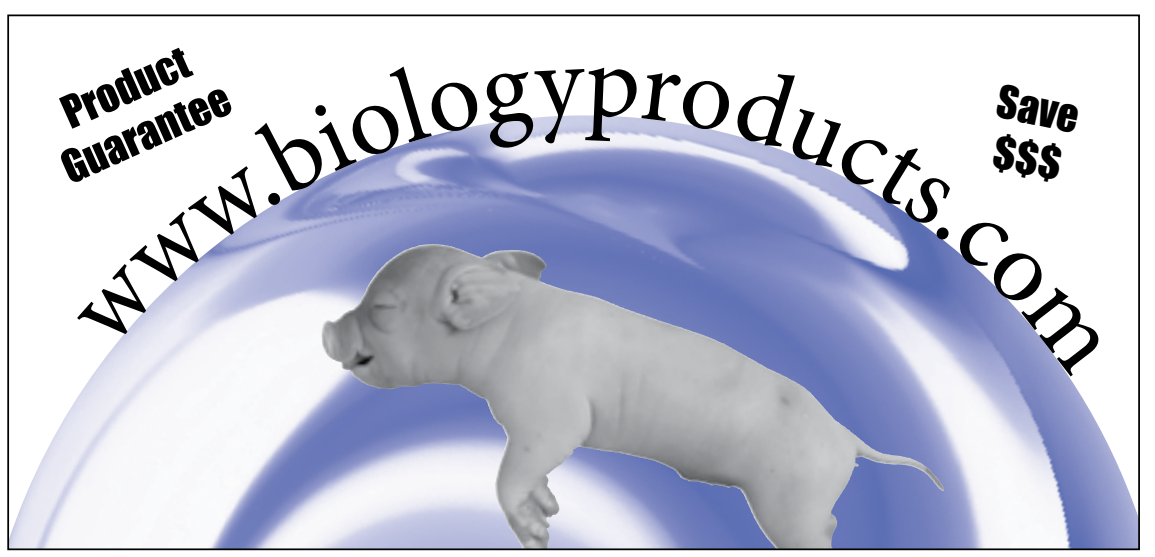

